\title{
Study on Evaluation System of Green Port Development
}

\author{
Guo Xu, Zhao Dadi* \\ Key Laboratory of Environmental Protection in Water Transport Engineering Ministry of Communications, \\ Tianjin Research Institute of Water Transport Engineering, Tianjin 300456, China
}

\begin{abstract}
Green ports are sustainable ports that achieve a good balance between environmental protection and economic benefits. With the deepening of the green port construction work, in order to study the green port evaluation system, through a large number of port field research, based on the actual situation of Port in China, the "Green Port Grade Evaluation Standard" (JTS/T105-4-2013) was revised, by means of weight assignment for different types of wharfs, the evaluation system at the level of port group is established to solve the limitation that the original standard can only evaluate specialized wharfs, and to realize the evaluation of large port groups with multiple wharfs. Finally, based on the above evaluation system, a port group is selected to evaluate and verify the integrity and correctness of the evaluation system.
\end{abstract}

\section{Introduction}

Green port refers to the port where the environment and economic development can coexist harmoniously. In order to reflect the green development level of the port comprehensively, objectively and accurately, it is necessary to carry out quantitative evaluation on the green development level of the port. At present, some research institutes and universities have made some achievements in this field. Zhen etc ${ }^{[1]}$. from infrastructure, development environment, wisdom, technology, service level, low carbon performance in five aspects, according to the theory of fuzzy information entropy, calculate the index of system layer of information entropy and weights and eight representative national port competitive ability, the integrated evaluation in 2013 and at the port of Fuzhou in Fujian province as an example of horizontal comparison and vertical sequence analysis. Huang, etc ${ }^{[2]}$. In view of the existing evaluation index system of port competitiveness ignore port on resources and environment have been the constraints of the evaluation method and ignore possible interaction relationship between indicators, in building a green port competitiveness evaluation index system on the basis of the hierarchical network analysis model to evaluate the competitiveness of the green port, and gives the evaluation method in Super Decisions software implementation process. $\mathrm{Xu}{ }^{[3]}$ set up a system of indicators based on strength, sexual, affordable and characteristic index 4 categories such as index of green port evaluation index system, the integrated use of analytic hierarchy process and fuzzy evaluation method, constructs the hierarchical fuzzy comprehensive evaluation model, makes an analysis of the existing green port construction of Qinhuangdao port, discusses the future development model, for many dissenting
Confucian port and Bohai sea port group of green low carbon construction provides guidance basis.

In recent years, port enterprises have made great efforts to promote the development of green ports by means of port electricity ${ }^{[4-5]}$, clean energy utilization ${ }^{[6]}$ and preparation of emission list. Therefore, based on the full investigation of the development of green ports in China, this paper modifies some clauses of the standard JTS / t105-4-2013 of green port rating evaluation standard, and introduces the evaluation method of port group to form a new one Port green development evaluation system.

\section{Overall modification description}

This part is modified based on the evaluation content in JTS/t105-4-2013, mainly including three parts:

(1) streamline the standard architecture

In the original standard system, the "content" part (including strategy, culture, environmental protection, energy saving, low-carbon, system, system, effect and level) will be classified and deleted.

(2) content modification

Revise the contents of "idea", "action", "management" and "effect".

\section{1 "concept" section}

In the actual evaluation process, the "strategic planning" and "work plan" part of the certification materials provided by most enterprises are the same, resulting in the duplication of the evaluation content, so the "work plan" part is deleted.

At the same time, the "strategic planning" part of the group level should be used in planning, the lack of port planning requirements of the enterprise itself, thus, to increase the evaluation standard of leading, port

\footnotetext{
*Corresponding author: 18630836305@163.com
} 
enterprises are expected to release planning accordingly, add 10 points of "strategic planning" part, and "foreign public release on the level of wharf green development special planning, $21 \sim 30$ points" the evaluation criteria.

In addition, in the "special fund" part, most of the dock enterprises lack a special budget for low-carbon and environmental protection, but only as a part of other budget costs. Therefore, in order to increase the guidance of evaluation standards, port enterprises are required to set up a special budget for energy conservation and environmental protection, and to increase the budget for investment in energy conservation, emission reduction and green port construction, which is $21-25$ points ( 5 points for the special fund).

In the actual evaluation, it was found that "green port concept is integrated into the enterprise's operation and management system" in the original standard, and the green plan released by the enterprise all contains such contents, causing repeated evaluation, so it was deleted.

Part of the materials provided by enterprises to "actively fulfill social responsibilities and build a green port image" are also mostly publicity activities, so this part is integrated into the "special publicity activities" in the "publicity activities", and according to the richness of the content of the activities, the participants, as appropriate, according to the standard score.

\section{2 "action" section}

In this part, all kinds of specialized wharves need to be evaluated separately. The modifications involved in each specialized wharf include:

(1) to facilitate the operation, in the original standard "article $\mathrm{X}$ and above, $\mathrm{X}$ points, each a $\mathrm{xx}$ other measures, according to satisfy a meter" scoring method become an index of each index calculated each are enforced, and then the average are enforced and the score multiplied to get the score, such as adding a similar project, according to complete a project.

(2) in order to reflect the importance of safety emergency response, the requirements for emergency plan and equipment in "pollution control" are changed to "formulate environmental pollution emergency response plan and ship oil spill emergency response plan".

(3) in the actual evaluation process, it was found that the comprehensive utilization of dredged soil was mostly carried out uniformly by the group, rather than by a single wharf company. Therefore, the specific methods of dredged soil and sludge comprehensive utilization were removed from the "comprehensive utilization" part.

(4) for the implementation of the Ministry of Transport of printed and distributed to the ship and port pollution prevention and control of special operation plan (2015-2020) and the implementation of port vessel pollutant receiving disposal announcement concerning the work related content, the index of "conservation" in "taking protective measures on the waters of the ecological environment in the wharf apron" part is modified to "have the ability to ship to receive, transport and disposal of pollutants".
(5) in the actual evaluation process, since most of the available waste heat comes from boilers, and most of the boilers in Tianjin port have been out of service, the words "using waste heat for heating and heating" in "auxiliary facilities" are deleted.

Modifications to different specialized terminals include:

\section{(1) container terminal}

Since most ports in Tianjin have carried out RTG "oil to electricity" and used diesel to drive less, the "wheel container gantry crane adopts diesel speed control technology according to load" is changed to "battery transfer" technology.

According to the investigation results of the major container terminals in Tianjin, the specific requirements of "one towing, double hanging" and "direct loading and unloading" were combined into "automatic container loading and unloading technology".

(2) bulk terminal

To promote the development of the new technology, "the crane will adopt potential energy recovery or ultracapacitor technology." It is divided into two items: "crane adopts applied potential energy recovery technology" and "crane applies energy storage technology". Due to the small coverage of "direct installation and direct retrieval", the "adopt direct installation and direct retrieval" operation process is deleted.

\section{3 "Administration" section}

Through the investigation of Tianjin port, it is found that the organization setting is more important than the personnel allocation in the management process, so the score in the column of "management organization" in the original standard is modified accordingly.

In order to encourage port enterprises to carry out the certification of energy management system, an item of "carrying out the certification of energy management system" is added in this part.

\section{4 "Effect" section}

In this part, the "effectiveness" part of the original standard is deleted. The main reason is that the overall environmental protection and energy conservation work of tianjin port is well carried out and the space for improvement is limited. While this part is mainly an index of all kinds of annual average decline rate, which is unfair in comparison with the dock where the environmental protection and energy conservation work is limited.

At present, port enterprises in Tianjin port must use the wastewater for themselves or discharge it to the sewage treatment plant. If the COD discharge concentration is no greater than $\mathrm{Cm}, 12$ points are obtained; If the value is greater than $\mathrm{C} 0$, no score will be obtained. In addition, "the utilization rate of nontraditional water resources should not be less than $30 \%$, which is 4 points; Less than $10 \%$, no score;" And "the proportion of the greening area of the port area in the greening area shall be no less than $90 \%$. Less than $85 \%$, 
no score "and" ecological protection "part repeated, so deleted.

\section{Construction of port group evaluation system}

For the green port grade evaluation at the level of the port group, this study first scored each port in the group according to the grade evaluation requirements. Based on the throughput, the average scores of the bulk terminals, container terminals and liquid bulk terminals in the group were determined. The calculation method is as follows:

$$
\mathrm{P}_{i}=\sum \frac{P_{i, j} T_{i, j}}{\sum_{j=0}^{j=m} T_{i, j}}
$$

$\boldsymbol{i}$ : the types of piers included in the port group, Including bulk terminals, Container terminal, liquid bulk terminal.

$\boldsymbol{P}_{\boldsymbol{i}, \boldsymbol{j}}$ : score of $J$ terminal (type $\boldsymbol{i}$ )

$\boldsymbol{T}_{\boldsymbol{i}, \boldsymbol{j}}$ : throughput of $J$ terminal (type $\boldsymbol{i}$ )

According to the previous green port grade evaluation cases and the survey results of various terminals, the container terminals and liquid bulk terminals have a high degree of automation. In contrast to the green port construction of bulk terminal, the bulk terminal should be regarded as the key point of green port construction at the level of port group. Therefore, in this study, when grading the group's wharf level, different weights are set for the average scores of various wharfs, and the formula for calculating the total score $\boldsymbol{P}$ of the port group is as follows:

$$
P=\sum 0.5 P_{\text {bulk }}+0.5 P_{\text {container }}+0.5 P_{\text {Liquid bulk }}
$$

Table 1. Port Group Rating Requirements

\begin{tabular}{|c|c|c|c|}
\hline $\begin{array}{c}\text { evaluation } \\
\text { content }\end{array}$ & $\mathbf{3}$ star & 4star & $\mathbf{5}$ star \\
\hline $\begin{array}{c}\text { composite } \\
\text { scores } \boldsymbol{E}\end{array}$ & $75 \leqslant \boldsymbol{E} \leqslant 85$ & $85 \leqslant \boldsymbol{E} \leqslant 95$ & $\boldsymbol{E} \geqslant 95$ \\
\hline $\begin{array}{c}\text { bulk terminal } \\
\text { scores } \boldsymbol{P}\end{array}$ & $75 \leqslant \boldsymbol{P} \leqslant 85$ & $85 \leqslant \boldsymbol{P} \leqslant 95$ & $\boldsymbol{P} \geqslant 95$ \\
\hline proportion $\boldsymbol{S}^{1}$ & $\boldsymbol{S} \geqslant 80 \%$ & $\boldsymbol{S} \geqslant 90 \%$ & $\boldsymbol{S}=100 \%$ \\
\hline $\begin{array}{c}\text { development } \\
\text { planning }\end{array}$ & - & - & $\checkmark 3$ \\
\hline $\begin{array}{c}\text { special financial } \\
\text { support }\end{array}$ & $\checkmark$ & $\checkmark$ & $\checkmark$ \\
\hline $\begin{array}{c}\text { development } \\
\text { report }\end{array}$ & $\checkmark$ & $\checkmark$ & $\checkmark$ \\
\hline ISO14001 ${ }^{2}$ & - & $\checkmark$ & $\checkmark$ \\
\hline
\end{tabular}

note:

1. The proportion of three - star or above wharfs in the group

2. The port group carried out environmental certification (ISO14001)

3. " $\checkmark$ " indicates that the project must have, “——No mandatory requirement.
The overall score of the terminal enterprise decreased from 94.3 to 90.23 , mainly due to (Table 3 ):

(1) The main reason for the decline in the score of the concept part is the introduction of the special green development plan emphasizing the wharf level, and the reduction of part of the repeated calculation.

(2) The score of the action part decreased a lot, mainly due to the change of the scoring method, as well as the addition of the factors such as "making the emergency plan for ship oil spill", "having the ability to receive, transfer and dispose the ship's pollutants" and the cancellation of "adopting the technology of replacing oil with electricity for the rubber tyred container gantry crane".

\subsection{Port group evaluation example and analysis}

Taking a port group as an example, the port group has a special plan for green development, set up a special fund for green development, published an annual green development report, established a target assessment system and carried out environmental certification.

The group has 10 subordinate terminals, including 4 bulk terminals, 5 container terminals and 1 liquid bulk terminal. The specific scores and ratings are shown in the following table:

Table 2. The value of $f$ under different relative humanity

\begin{tabular}{|c|c|c|c|}
\hline Terminal type & Throughput & Score & Star level \\
\hline Bulk A & 2802 & 82 & Three-star \\
\hline Bulk B & 1500 & 85 & Four-star \\
\hline Bulk C & 1482 & 82 & Three-star \\
\hline Bulk D & 987 & 70 & $/$ \\
\hline Container A & 1452 & 90 & Four-star \\
\hline Container B & 1689 & 93 & Four-star \\
\hline Container C & 1256 & 96 & Five-star \\
\hline Container D & 2541 & 76 & Three-star \\
\hline Container E & 1658 & 75 & Three-star \\
\hline Liquid bulk A & 322 & 85 & Three-star \\
\hline
\end{tabular}

Thus, the group's total score of 82.79 , three-star or above terminals accounted for $90 \%$, the bulk terminal score of 80.92 , the final three-star.

Contrast evaluation qualification, three-star wharf of the port group and other limited conditions are also conform to the requirements of the four-star pier, but contrast four-star port group score requirements, lower scores of the overall score and bulk terminals, thus it can be seen that bulk cargo wharf green development level is low, through increasing port group, bulk terminal scoring weight, which can effectively promote the wharf group green port construction.

\section{Results and discussion}

\subsection{Modification of "concept"}


Table 3. Summary of the scores of each Wharf under the Port Group

\begin{tabular}{|c|c|c|c|c|c|c|c|}
\hline \multirow{2}{*}{ project } & \multicolumn{3}{|c|}{ now the score } & \multicolumn{4}{|c|}{ the original score } \\
\hline & indicators & score & total & content & indicators & score & total \\
\hline \multirow{4}{*}{$\begin{array}{c}\text { concept } \\
10 \%\end{array}$} & a special fund & 25 & \multirow{4}{*}{88} & \multirow{2}{*}{ strategic } & a special fund & 20 & \multirow{4}{*}{98} \\
\hline & 1 & 1 & & & the work plan & 15 & \\
\hline & the enterprise culture & 13 & & \multirow{2}{*}{ culture } & the enterprise culture & 18 & \\
\hline & propaganda activity & 15 & & & propaganda activity & 10 & \\
\hline \multirow{6}{*}{$\begin{array}{l}\text { action } \\
40 \%\end{array}$} & pollution control & 18.4 & \multirow{6}{*}{84.6} & \multirow{3}{*}{$\begin{array}{c}\text { environmental } \\
\text { protection }\end{array}$} & pollution control & 19.6 & \multirow{6}{*}{92.7} \\
\hline & $\begin{array}{c}\text { comprehensive } \\
\text { utilization }\end{array}$ & 9.7 & & & $\begin{array}{c}\text { comprehensive } \\
\text { utilization }\end{array}$ & 9.8 & \\
\hline & $\begin{array}{c}\text { ecological and } \\
\text { environmental } \\
\text { protection }\end{array}$ & 3.3 & & & $\begin{array}{c}\text { ecological and } \\
\text { environmental } \\
\text { protection }\end{array}$ & 5.0 & \\
\hline & auxiliary facilities & 10.8 & & energy saving & auxiliary facilities & 10.3 & \\
\hline & alternative fuel & 2.5 & & \multirow{2}{*}{ low carbon } & alternative fuel & 8.1 & \\
\hline & renewable energy & 4.8 & & & renewable energy & 4.9 & \\
\hline \multirow{2}{*}{$\begin{array}{c}\text { management } \\
15 \%\end{array}$} & audit certification & 25 & \multirow{2}{*}{93} & system & audit certification & 20 & \multirow{2}{*}{93} \\
\hline & incentive constraints & 5 & & institution & incentive constraints & 10 & \\
\hline \multirow{4}{*}{$\begin{array}{c}\text { effect } \\
35 \%\end{array}$} & 1 & 1 & \multirow{4}{*}{96.1} & \multirow[t]{2}{*}{ results } & $\begin{array}{c}\text { environmental } \\
\text { protection }\end{array}$ & 20 & \multirow{4}{*}{95.7} \\
\hline & 1 & 1 & & & low carbon saving & 20 & \\
\hline & $\begin{array}{c}\text { ecological } \\
\text { environmental } \\
\text { protection }\end{array}$ & 50.0 & & \multirow[t]{2}{*}{ level } & $\begin{array}{c}\text { ecological } \\
\text { environmental } \\
\text { protection }\end{array}$ & 28.8 & \\
\hline & low carbon saving & 46.1 & & & low carbon saving & 26.9 & \\
\hline
\end{tabular}

note:because only the parts with different scores are displayed, the score does not correspond to the total score.

\section{Conclusion}

Through the modification of the original standard, a port green development evaluation system more suitable for the characteristics of port is formed, and an evaluation method for port group is put forward, which solves the limitation that the original standard can only evaluate the port, and expands the evaluation scope and comparison method. It can be used to evaluate the green development effect of port. Through the modification of some clauses in the evaluation system, it can be extended to other ports in the country.

\section{References}

1. $\mathrm{Xu} \mathrm{Z,} \mathrm{Zhang} \mathrm{S}, \mathrm{Xu} \mathrm{Y}$. Research on competitive capacity of port logistics system based on fuzzy information entropy theory-Take Fuzhou port intelligent logistics and low-carbon port construction as an example (Acta Analysis Functionalis Applicata),2014,16(2):129-137.

2. Huang $\mathrm{H}$, Mo D, Cheng W. Competitiveness evaluation of green ports based on ANP model , (Technical Economy) ,2017,36(2):117-122.
3. Zhao X. Study on evaluation model and development model of green and low-carbon port index, (Port Engineering Technology) 2017, 54(5):80-83.

4. Liu L L etc, Study on methodology of voluntary emission reduction of greenhouse gases from shore power projects (journal of waterway and harbor), 445-449,2019,40(4).

5. Sun H T etc, Research on the inrush current and suppression method of frequency conversion shore powe (journal of waterway and harbor) 556-564, 2019,40(5).

6. Peng $\mathrm{Y}$ etc, Study on port power consumption strategy for comprehensive utilization of marine energy, (journal of waterway and harbor) 439-444, 2019,40(4). 